\title{
USO DE LEVEDURAS (Saccharomyces cerevisae), PAREDE CELULAR DE LEVEDURAS (SSCW), ÁCIDOS ORGÂNICOS E AVILAMICINA NA ALIMENTAÇÃO DE FRANGOS DE CORTE
}

\section{Use of yeast (Saccharomyces cerevisae), yeast cell wall (SSCW), organic acids and avilamycin in broilers feeding}

\author{
RIBEIRO, R.P'.; FLEMMING, J.S. ${ }^{2}$; BACILA, A.R ${ }^{2}$. \\ ${ }^{1}$ Cooperativa Central Oeste Catarinense. Chapecó-SC \\ ${ }^{2}$ Organnact -Sheep, Curitiba- PR \\ Endereço para correspondência: José Sidney Flemming - flemmingjs@yahoo.com.br
}

\section{RESUMO}

Foi realizado um estudo com 2.520 frangos de corte machos para verificar o efeito do uso de simbióticos na alimentação de frangos de corte (leveduras Saccharomyces cerevisae e mananoligossacarideos), comparativamente a parede celular de leveduras acrescido de aluminosilicato de sódio e cálcio, uma mistura de ácidos orgânicos constituída por ácido lático, acido cítrico e ácido fumárico, um promotor de crescimento (Avilamicina) e um controle negativo. As dietas foram a base de milho e farelo de soja. Foi utilizado um delineamento inteiramente casualizado e os dados obtidos avaliados pela análise da variância e teste de Tukey ao nível de $5 \%$. Os parâmetros avaliados foram: consumo de ração, ganho de peso, conversão alimentar e Fator de Eficiência Europeu (EEF). No estágio inicial de vida das aves (1 a 21 dias de idade), a inclusão do promotor de crescimento apresentou um resultado inferior aos demais tratamentos testados, que não diferiram entre si. Considerando-se o período total (1 a 42 dias de idade) a análise do Fator de Eficiência Europeu que sumariza todos os resultados zootécnicos e econômicos dos tratamentos, permite concluir que a substituição de antibióticos por simbióticos (leveduras e mananoligossacarídeos) é uma alternativa viável e econômica.

Palavras-chave: Parede celular, leveduras, promotores de crescimento.

\begin{abstract}
A study was accomplished with 2.520 chickens males to verify the effect of the simbiótics use in the feeding of males chickens (yeasts Saccharomyces cerevisae and mananoligossacharides), comparatively the added of aluminosilicate of sodium cellular wall of yeasts and calcium, a mixture of organic acids constituted by lactic acid, citric acid and fumaric acid, a growth promoter (Avilamicin) and a negative control. The diets were the corn base and soy crumb. A completely randomized experimental design was used, and the obtained data were evaluated by analysis of variance and test of Tukey at a level of $5 \%$. The appraised parameters were: ration consumption, weight gain, alimentary conversion and European Factor of Efficiency (EEF). In the initial apprenticeship of life of the birds ( 1 to 21 days of age), the growth promoter's inclusion presented an inferior result to the other tested treatments, that you/they didn't differ amongst themselves. Being considered the total period ( 1 to 42 days of age) the analysis of the European Factor of Efficiency that whole summarize the results and economical of the treatments, it allows to end that the substitution of antibiotics for simbiotics (yeasts and mananoligossaccharides) it is a viable and economical alternative
\end{abstract}

Key words: Cellular wall, yeasts, growth promoters. 


\section{INTRODUÇÃO}

O uso de drogas e ou antibióticos como promotores de crescimento na alimentação de frangos tem sido largamente utilizado nas últimas décadas. Drogas empregadas em terapêutica veterinária foram e são usadas o que determinou 0 aparecimento de formas microbianas resistentes e prejudiciais à saúde e terapia humana, despertando a atenção das autoridades governamentais envolvidas com a Saúde Pública. Os sucessivos relatos de problemas sanitários decorrentes da resistência microbiana a antibióticos, fez com que as autoridades sanitárias brasileiras instituíssem um comitê formado por representantes de entidades envolvidas com a alimentação animal e indústria de rações, criando o Plano Nacional de Controle de Resíduos Biológicos (PNCRB), o qual, através de portarias ministeriais, dita as normas pelas quais a indústria deverá adequar-se às exigências do mercado internacional (Severo, 2000; Miltenburg, 2000). Em junho de 1999, a Comunidade Econômica Européia (CEE) baniu o uso de alguns antibióticos na alimentação de aves e em 2006, através da IN 65 publicada no DOU em 24/11/06, o Ministério da Agricultura e Abastecimento (MAPA) restringiu o uso de antibióticos como promotores de crescimento na alimentação de animais domésticos, com implicações para a indústria de carnes no Brasil (Halfhide, 2003).

A proibição do uso de promotores de crescimento para depressão da microbiota indesejável determinou que pesquisadores e nutricionistas buscassem novas alternativas, entre as quais a cultura de formas de microorganismos desejáveis que possibilitem 0 equilíbrio no trato gastrintestinal, atuando como uma barreira defensiva e realizando uma competição pelo espaço na mucosa intestinal com as bactérias patogênicas de modo a evitar distúrbios que venham a afetar a digestão e absorção de nutrientes (SANTIN et al., 2001).

Microorganismos como as leveduras do gênero Saccharomyces cerevisae têm sido descritos como favorecedores do desempenho de frangos de corte e redutores de microorganismos enteropatogênicos (Okpokwasili, 1996). Line et al. (1998) constataram que a utilização de leveduras do gênero Saccharomyces boulardi na dieta de frangos provocou uma redução do nível de Salmonellas de $53,3 \%$ para $40,0 \%$ quando em condições de estresse no transporte das aves para o abate.

Reig e Anesto (2002) citam que as leveduras do gênero Saccharomyces cerevisae atuam favorecendo a ação de microorganismos fermentadores da celulose com aumento de até $25 \%$ no número de bactérias digestoras da celulose, melhorando a concentração total de ácidos graxos voláteis, e baixando o $\mathrm{pH}$ do meio intestinal. Nesse caso ocorre um incremento na produção de ácido acético e outros ácidos graxos voláteis (AGV) no intestino, favorecendo uma situação de eubiose com diminuição da ação de bactérias indesejáveis como as do gênero Clostridium.

Estudos de Pelicia et al (2004) demonstraram que a suplementação com culturas de Saccharomyces cerevisae aumentava o valor nutricional da proteína da dieta através do aumento da digestibilidade, resultando no dobro da percentagem de nitrogênio digerido e retido no organismo. A avaliação do perfil de aminoácidos plasmáticos após uma semana do uso de leveduras resultou em aumento significativo do nível de aminoácidos, principalmente lisina. Guo e Liu (1997), empregando leveduras Saccharomyces cerevisae var. chromium, obtiveram uma redução nos efeitos negativos do estresse calórico em frangos de corte.

A utilização de carboidratos não digestíveis como parede celular de plantas 
e leveduras, oligossacarídeos representados

classificados

complexos

principalmente como

$$
\text { e }
$$

por

(FOS)

e

que frutoligossacarídeos mananoligossacarídeos

(MOS), apresentam a propriedade de se ligarem à fímbria das bactérias patogênicas e inibirem a colonização do trato gastrintestinal por microorganismos indesejáveis, reflete a ação como prebióticos (Silva, 2000). A parede celular de leveduras (SCCW) contém oligossacarídeos que são, de modo geral, obtidos a partir da ação de enzimas como as glicosiltransferases (transglicosilases), utilizando-se produtos agrícolas como a sacarose e o amido como substratos em processos fermentativos, sintetizando glicomananoproteínas

mananoligossacarídeos, que não podem ser hidrolisados pelas enzimas digestivas (Martin, 1994).

Santin et al. (2001), em estudo realizado com frangos alimentados com $1 \mathrm{e}$ $2 \mathrm{~kg}$ de SCCW/tonelada de ração, constataram efeitos significativos no desempenho zootécnico e integridade da mucosa intestinal indicando níveis de inclusão de $2 \mathrm{~kg}$ de SCCW/tonelada de ração. Pelicia et al (2004) demonstraram que as bactérias indesejáveis, presentes na mucosa do trato gastrintestinal, têm a sua fímbria ligada a receptores contendo Dmanose e desta forma os produtos contendo açúcares insolúveis como a manose, podem ser utilizados para reduzir a colonização por bactérias enteropatogênicas. Spring et al. (2000) constataram que 0 uso de mananoligossacarídeos (MOS), derivados da parede celular de Saccharomyces cerevisae, quando adicionados à dieta de frangos, reduzia a presença de Salmonella typhimurium no ceco das aves. Resultados semelhantes foram relatados por Fernandez et al. (2003), em um estudo com poedeiras onde foram utilizados $2,5 \%$ de mananoligossacarídeos na dieta.
A alternativa do uso dos acidificantes e ácidos orgânicos como agentes modificadores da flora provocando diminuição dos microorganismos provocadores da disbiose têm sido bem aceita por pesquisadores e nutricionistas. Os ácidos orgânicos ou inorgânicos são adicionados à dieta, visando redução do $\mathrm{pH}$ do trato digestivo com objetivo de facilitar a digestão e controlar a microbiota.

A quantidade de acidificante a ser adicionada à ração depende do seu $\mathrm{pH}$ e de sua capacidade tamponante. Dos diversos ácidos orgânicos utilizados na alimentação de suínos, o ácido fumárico e o ácido cítrico são os mais utilizados, enquanto o ácido fosfórico é o ácido inorgânico mais comum. Existem várias citações de melhoria no ganho de peso e eficiência alimentar. O modo de ação desses ácidos parece ser através da acidificação da dieta com redução do $\mathrm{pH}$ estomacal e aumento na ação da pepsina na digestão de peptídeos; com a redução do $\mathrm{pH}$ estomacal há redução na taxa de esvaziamento do estômago, aumentando a digestão de peptídeos. Essa redução de $\mathrm{pH}$ no estômago pode reduzir a proliferação de microorganismos indesejáveis. Geralmente as bactérias alvo (patógenas) são inativadas por mecanismos que incluem a interferência na parede celular, membrana citoplasmática, e funções específicas do citoplasma associadas com a sua replicação, tais como síntese protéica (Davidson, 2001). Os ácidos orgânicos e inorgânicos podem aumentar a conservação dos ingredientes e rações. 0 ácido cítrico e fumárico são acidificantes que podem ser empregados nas rações pré-iniciais. Entretanto, o efeito do acidificante na dieta sobre o desempenho dos suínos, depende da idade dos animais, da composição da dieta e da presença ou ausência de antimicrobianos. As quantidades de acidificantes empregadas dependem da capacidade em reduzir o $\mathrm{pH}$ (Bellaver, 2000).

O objetivo do presente estudo é 
investigar os efeitos de leveduras (Saccharomyces cerevisae), comparativamente a outros aditivos nos parâmetros zootécnicos de frangos de corte.

\section{MATERIAL E MÉTODOS}

O experimento foi conduzido no aviário experimental da Cooperativa Central Oeste Catarinense (Aurora) em Chapecó, Santa Catarina.

Foram utilizados 2.520 pintos (Machos Coob) com peso médio inicial aproximado de $48 \mathrm{~g}$ oriundos de matrizes de 50 semanas de idade, distribuídos em 6 tratamentos com 6 repetições com 70 aves por unidade experimental.

As aves foram alojadas em um galpão de construção mista cimento e madeira, tela e madeira, com um corredor central de serviço, dividido em boxes, recobertos de cama de maravalha, com os comedouros e bebedouros utilizados obedecendo as especificações dos fabricantes. Utilizou-se uma lotação de 10 aves por $\mathrm{m}^{2}$. Para aquecimento inicial, foram empregadas campânulas com lâmpadas de acordo com o manejo. O aquecimento das aves foi mantido até os 21 dias de idade. A ração utilizada (tabela 1), isonutritiva, à base de milho e soja, foi formulada de acordo com as recomendações de Andriguetto et al (2000), atualmente em uso na Cooperativa.

Os tratamentos utilizados foram: T1Controle negativo (sem promotor de crescimento); T2- Controle positivo (Avilamicina, $10 \mathrm{ppm} / \mathrm{kg}$ de ração); T3Mistura de leveduras e mananoligossacarídeos ( $50 \%$ de leveduras e $50 \%$ de MOS)uso de $2 \mathrm{~kg} / \mathrm{ton}$ de ração; T4- Mistura de leveduras vivas e SCCW $\left(1 \times 10^{10} \quad\right.$ UFC/g de Saccharomyces cerevisae associado à $50 \%$ de parede celular de leveduras), com uso de $1 \mathrm{~kg} / \mathrm{ton}$ de ração; T5- Mistura de ácidos (lático 1,3\%, fumárico o,5\% e citrico $5 \%$ ), uso de 1 $\mathrm{kg}$ /ton de ração; T6- mistura de aluminosilicato sódico e cálcico (HSCAS) com mananoligossacarídeos $(70 \%$ de HSCAS e $30 \%$ de MOS), uso de $0,3 \mathrm{~kg}$ por tonelada de ração.

Nos tratamentos T3, T5 e T6, o produto foi misturado em escala industrial pelo fabricante em linha de produção de aço inox própria para aditivos. O uso da mistura de leveduras (T4) segue exigência de registro do Ministério da Agricultura e está de acordo com a portaria que regulamenta o uso de microorganismos.

As aves e a ração foram pesadas no alojamento aos 7, 21 e 42 dias de idade, para obtenção dos dados do desempenho zootécnico: consumo de ração, ganho de peso, conversão alimentar e Fator de Eficiência Europeu (EEF) no final do experimento avaliado pela fórmula descrita no manual da ROSS BREEDERS (1990).

O Fator de Eficiência Europeu (EEF) somente foi efetuado no fim do experimento por necessitar de dados de mortalidade e viabilidade (100 mortalidade) do lote, aplicado a fórmula abaixo:

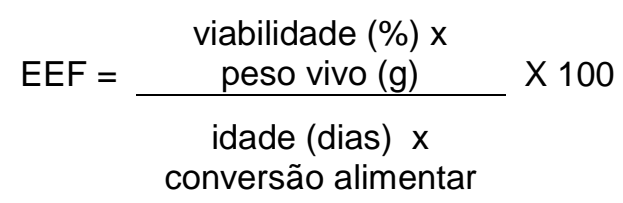

O Delineamento experimental foi Inteiramente Casualizado (DCC). A análise estatística dos resultados zootécnicos dos animais (peso, ganho de peso diário, consumo de ração, conversão alimentar e mortalidade), obtidos ao longo do experimento por pesagens, foram submetidos à análise da variância (SAS,1998), sendo as médias dos tratamentos, para as diferentes variáveis, comparadas através do teste de Tukey ao nível de $5 \%$ de probabilidade $(P<0,05)$. 
Tabela 1 - Composição das dietas experimentais de acordo com as fases de criação das aves (kg).

$\begin{array}{cccc}\text { Pré-inicial } & \text { Inicial } & \text { Crescimento } & \text { Final } \\ \text { (1 a } 7 \text { dias }) & (8 \text { a } 21 \text { dias }) & (22 \text { a } 35 \text { dias }) & \text { (36 dias }- \text { abate })\end{array}$

\begin{tabular}{|c|c|c|c|c|c|c|}
\hline \multicolumn{7}{|l|}{ Ingrediente } \\
\hline \multicolumn{2}{|l|}{ Milho } & 595,0 & 647,0 & 684,0 & & 670,0 \\
\hline \multicolumn{2}{|l|}{ Farelo de soja } & 310,0 & 237,0 & 203,0 & & 210,0 \\
\hline \multicolumn{2}{|l|}{ Farinha de carne } & 27,0 & 34,0 & 50,0 & & 50,0 \\
\hline \multicolumn{2}{|l|}{ Farinha de vísceras } & 20,0 & 40,0 & 25,0 & & 20,0 \\
\hline \multicolumn{2}{|l|}{ Óleo vegetal } & 25,0 & 25,0 & 25,0 & & 25,0 \\
\hline \multicolumn{2}{|l|}{ Sal comum } & 3,0 & 3,0 & 3,0 & & 3,0 \\
\hline \multicolumn{2}{|l|}{ Calcário calcítico } & 7,0 & 5,0 & 2,5 & & 2,5 \\
\hline \multicolumn{2}{|l|}{ Fosfato bicalcico } & 6,0 & 2,0 & & & \\
\hline \multicolumn{2}{|l|}{ Premix $^{1}$} & 7,0 & 7,0 & 7,0 & & 7,0 \\
\hline \multicolumn{7}{|l|}{ Análise calculada $^{2}$} \\
\hline & 21,8 & 20,7 & 19,0 & & 18,2 \\
\hline & & 3020 & 3100 & 3150 & & 3200 \\
\hline \multicolumn{2}{|l|}{$\begin{array}{l}\text { Energia Metabolizável (kcal) } \\
\text { Lisina digestivel \% }\end{array}$} & 1,18 & 1,13 & 0,97 & & 0,94 \\
\hline \multicolumn{2}{|l|}{ Metionina digestivel \% } & 0,50 & 0,40 & 0,35 & & 0,33 \\
\hline \multicolumn{2}{|l|}{ Cálcio \% } & 0,97 & 0,90 & 0,90 & & 0,90 \\
\hline \multicolumn{2}{|l|}{ Fósforo utilizável \% } & 0,43 & 0,42 & 0,42 & & 0,42 \\
\hline \multicolumn{7}{|c|}{$\begin{array}{l}\text { NOTAS: }{ }^{1} \text { Premix vitamínico e mineral, quantidade adicionada por kg de ração : Vit A } 7000 \text { UI, Vit D3 } 1400 \\
\text { Ul, Vit E } 18 \mathrm{mg} \text {, Vit K } 2,0 \mathrm{mg} \text {, tiamina } 2 \mathrm{mg} \text {, riboflavina } 5 \mathrm{mg} \text {, piridoxina } 4 \mathrm{mg} \text {, cianocobalamina } 1500 \mathrm{mcg} \\
\text { biotina } 0,20 \mathrm{mg} \text {, colina } 2,00 \mathrm{~g} \text {, ácido pantotênico } 40 \mathrm{mg} \text {, niacina } 50 \mathrm{mg} \text {, ácido fólico } 1 \mathrm{mg} \text {, selênio } 0,30 \mathrm{mg} \text {, } \\
\text { iodo } 0,5 \mathrm{mg} \text {, ferro } 50 \mathrm{mg} \text {, cobre } 10 \mathrm{mg} \text {, zinco } 70 \mathrm{mg} \text {, manganês } 80 \mathrm{mg} \text {, potássio } 6,0 \mathrm{mg} \text {, sódio } 1,30 \mathrm{mg} \text {, D } \\
\text { metionina } 2,0 \mathrm{~g} \text {, lisina } 1,8 \mathrm{~g}{ }^{2} \text { Demais nutrientes seguem os conceitos de proteína ideal e nível energético } \\
\text { de acordo com Andriguetto et al, (2000) }\end{array}$} \\
\hline \multicolumn{7}{|c|}{$\begin{array}{l}\text { Tabela } 2 \text { - consumo de ração (cr), ganho de peso (gp) e conversão alimentar (ca) do inicio aos } 21 \text { dias de } \\
\text { idade das aves. chapecó-sc. }(n=2520) \text {. } 2006 \text {. }\end{array}$} \\
\hline \multirow[t]{2}{*}{ TRATAMENTOS } & \multicolumn{3}{|c|}{$1-7$ DIAS } & \multicolumn{3}{|c|}{ 1-21 DIAS } \\
\hline & $\mathrm{CR}(\mathrm{g})$ & GP $(g)$ & $C A(g / g)$ & $\mathrm{CR}(\mathrm{g})$ & $\mathrm{GP}(\mathrm{g})$ & $\mathrm{CA}(\mathrm{g} / \mathrm{g})$ \\
\hline T1 & 146,3 & 147,8 & 0,990 & 1272,9 & $1020,8^{\mathrm{a}}$ & 1,247 \\
\hline T2 & 147,8 & 147,5 & 1,003 & 1279,5 & $979,0^{\mathrm{b}}$ & 1,279 \\
\hline T3 & 144,7 & 149,3 & 0,969 & 1294,3 & $1033,0^{a}$ & 1,294 \\
\hline T4 & 146,5 & 147,5 & 0,969 & 1276,3 & $1031,8^{\mathrm{a}}$ & 1,276 \\
\hline T5 & 143,3 & 145,3 & 0,993 & 1280,6 & $1018,8^{\mathrm{a}}$ & 1,280 \\
\hline T6 & 146,5 & 149,2 & 0,982 & 1292,2 & $1028,0^{\mathrm{a}}$ & 1,292 \\
\hline Valor de $\mathrm{p}$ & 0,092 & 0,197 & 0,124 & 0,119 & 0,012 & 0,085 \\
\hline
\end{tabular}

NOTA: Médias seguidas de letras distintas diferem entre si significativamente ao nível de $5 \%$ pelo teste de Tukey.

\section{RESULTADOS E DISCUSSÃO}

Estágio de 1 a 7 dias e de 1 a 21 dias de vida das aves:

$\mathrm{Na}$ fase do início aos 7 dias de idade, não se constatou um efeito que caracterizasse uma diferença entre os tratamentos testados. Os dados estão demonstrados na Tabela 2. No estágio inicial de vida das aves até 21 dias de idade, a inclusão do promotor de crescimento apresentou um resultado inferior no parâmetro ganho de peso comparativamente aos demais tratamentos testados, que não diferiram entre si (tabela 2).

Estágio de 1 aos 42 dias de vida das aves: No período total de criação das aves (1 a 42 dias de idade), o ganho de peso entre os tratamentos não apresentou diferenças significativas. Os resultados do 
uso do promotor de crescimento se equivaleram aos demais tratamentos. Quanto aos demais parâmetros analisados os tratamentos não diferiram entre si, desde o início até os 42 dias de idade das aves. Os resultados estão demonstrados na tabela 3 .

Tabela 3 - Consumo de ração (CR), ganho de peso (GP) e conversão alimentar (CA) do inicio aos 42 dias de idade das aves. Chapecó-SC. $(n=2520)$. 2006.

\begin{tabular}{cccc}
\hline TRATAMENTOS & \multicolumn{3}{c}{$\mathbf{1 - 4 2}$ DIAS } \\
& CR $(\mathrm{g})$ & GP $(\mathrm{g})$ & CA $(\mathrm{g} / \mathrm{g})$ \\
\hline T1 & 5832,0 & 2989,2 & 1,951 \\
T2 & 5746,2 & 2924,3 & 1,965 \\
T3 & 5580,2 & 2957,2 & 1,887 \\
T4 & 5758,9 & 2954,8 & 1,949 \\
T5 & 5683,1 & 2961,5 & 1,919 \\
T6 & 5717,6 & 5683,1 & 1,915 \\
Valor de P & 0,235 & 0,098 & 0,110 \\
\hline
\end{tabular}

Considerando-se o EEF, entretanto, que é estimado apenas no fim do experimento e que resume todos os dados de produção de uma exploração avícola, verificou-se que o resultado em índice produtivo foi significativamente superior para os tratamentos T4 e T6. Estes mostraram-se com um maior índice comparativamente aos tratamentos com a mistura de ácidos orgânicos e promotor de crescimento (tabela 4).

Tabela 4- Viabilidade (V\%) e Fator de Eficiência Europeu (EEF) de 1 a 42 dias didade das aves. Chapecó-SC. $(\mathrm{N}=2520) .2006$.

\begin{tabular}{ccc}
\hline TRATAMENTOS & $\mathbf{V} \%$ & EEF \\
\hline T1 & $94,76^{\mathrm{b}}$ & $445^{\mathrm{b}}$ \\
T2 & $94,76^{\mathrm{b}}$ & $437^{\mathrm{b}}$ \\
T3 & $85,96^{\mathrm{a}}$ & $440^{\mathrm{b}}$ \\
T4 & $96,91^{\mathrm{b}}$ & $454^{\mathrm{a}}$ \\
T5 & $92,38^{\mathrm{b}}$ & $434^{\mathrm{b}}$ \\
T6 & $95,71^{\mathrm{b}}$ & $450^{\mathrm{a}}$ \\
Valor de P & 0,029 & 0,018 \\
\hline
\end{tabular}

NOTA: Médias seguidas de letras distintas diferem entre si significativamente ao nível de $5 \%$ pelo teste de Tukey.
Do início aos 21 dias de idade, 0 antibiótico proporcionou o pior ganho de peso, não diferindo, entretanto, quanto à conversão alimentar e consumo de ração. Os tratamentos contendo leveduras associadas com mananoligossacarídeos ou leveduras vivas (T3 e T4) em diferentes proporções, diferiram do uso da mistura de ácidos orgânicos. Estes resultados contradizem àqueles descritos na literatura e enfatizados há várias décadas que atribuem aos promotores de crescimento antibióticos melhoras no desempenho das aves em até 5\% (Martin, 1994; Silva, 2000).

Grigoletti et al. (2002) constataram melhora significativa no desempenho de frangos de corte quando alimentados com dietas contendo leveduras Saccharomyces cerevisae. . Flemming et al. (2005) utilizando leveduras vivas do gênero Saccharomyces cerevisae associadas a parede celular de leveduras (SCCW) refere melhora no desempenho das aves possivelmente devido à ação da parede celular que apresenta um sítio ligante competitivo com as bactérias. Estas bactérias ao se ligarem à SCCW não podem se ligar aos enterócitos, movendose com o bolo fecal e não colonizando o trato intestinal, exercendo, portanto, uma ação similar àquela do antibiótico (Newman, 1994; Ito et al. 2004).

Após os 21 dias, observa-se uma tendência à estabilidade da microbiota que permanece até os 35 dias, com os tratamentos não diferindo entre si (Soerjadi et al., 1992). Este efeito de estabilização da microbiota é atribuído à ação benéfica das bactérias da microbiota normal e leveduras, que produzem ácidos graxos de cadeia curta propiciando um meio e pH desfavoráveis à ação de bactérias indesejáveis, produzindo também 0 peróxido de hidrogênio e sulfito de hidrogênio com ação similar e evitando efeitos negativos no desempenho das aves. Alguns microorganismos produzem bacteriocinas, que são antibióticos próprios das bactérias, com ação local e inibição do 
crescimento de patógenos intestinais, que é bastante comum nas bactérias lácticas que tem o seu crescimento favorecido em ambiente eutrófico (SILVA, 2000).

No estágio do início aos 42 dias de idade, não se constatou diferenças quanto aos parâmetros estudados. Estudo de Canalli et al. (1996), avaliando a ação de probióticos sobre enterobactérias patogênicas, mostrou que aos 28 dias de idade, a microbiota de coliformes fecais ainda não era totalmente estável e que esta estabilidade só era atingida após os 40 dias de idade, explicando em parte o resultado benéfico do uso do promotor de crescimento. Após os 21 dias de idade os resultados não apresentaram diferenças significativas atribuindo-se uma depressão no crescimento de bactérias enterais indesejáveis a ação do antibiótico e a competição exclusiva dos probióticos e prebióticos. Subrata et al. (1997), comparando os efeitos de leveduras com antibióticos promotores de crescimento, não constaram qualquer efeito das leveduras Saccharomyces cerevisae em relação ao uso de antibiótico na ração. Resultados similares também são descritos por Latrille et al. (1996), os quais não constataram benefícios nos parâmetros ganho de peso, conversão alimentar e mortalidade quando do uso de diferentes doses de leveduras comparativamente ao uso de promotores de crescimento na alimentação de frangos de corte.

A ação benéfica dos antibióticos como promotores de crescimento na alimentação de aves é referida por vários autores (Day, 1992; Martin, 1994, Fernandez, 2003) e tem a característica de deprimir a microbiota intestinal, mantendo-a em níveis mínimos e facilitando a digestão enzimática e absorção de nutrientes; seu efeito é dependente do espectro de inibição microbiana do promotor, isto é, se é Gram positivo ou negativo. De modo geral, são utilizados em rações como promotores de crescimento os antibióticos com espectro Gram positivos e que atendem as recomendações descritas no FEED ADDITIVE COMPENDIUM (1995).

\section{CONCLUSÕES}

Os resultados deste experimento permitem concluir que a substituição de antibióticos por simbióticos (leveduras e mananoligossacarideos) é uma alternativa viável e econômica mostrada pelo Fator de Eficiência Europeu (EEF).

\section{REFERÊNCIAS}

ANDRIGUETTO, J.M.; $\quad$ FLEMMING,J.S.; SOUZA,G.A.; MINARDI, I.; ANDRIGUETTO J.L. Normas e Padrões de Nutrição e Alimentação Animal. Revisão 2000. Ministério da Agricultura e do Abastecimento. Brasília. MA/SARC/DFPA. 152p. 2000.

BELLAVER,C. O uso de microingredientes (aditivos) na formulação de dietas para suínos e suas implicações na produção e na segurança alimentar. Congresso Mercosur de Producción Porcina. 2000. Buenos Aires.

CANALLI, L. S.; FLEMMING, J.S.; MIRA, R.T.; BASILE, L.F. Alteração da microbiota intestinal de frangos de corte pela utilização de um probiótico na alimentação. Revista do Setor de Ciências Agrárias, Curitiba, v. 15, n.1, p.125-133, 1996.

DAY, C. A ; Competitive Exclusion in Poultry. A Review. Worcestershire: Life Care Products Ltd. 18p. 1992.

DAVIDSON, P. M. 2001.. Chemical preservatives and natural antimicrobial compounds. In Food Microbiology - Fundamentals and Frontiers. 2nd. Ed. American Society for Microbiology, Washington, DC. Cp. 29. p 593-627. 1994

ESHDAT, Y.; OFEK, L.; SHARON, N. Isolation of manose especific lecitin from Escherichia coli and is role in the adherence of bacteria in the epithelial cells. Biochemical Biophysical Research Communications, New York, v. 85, p. 1551-1559, 1978.

FEED ADDITIVE COMPENDIUM. Additives and their uses. Washington: D.C. 1995. 503p.

FERNANDEZ, J.; CRESPO, N. New advances in the application of probiotics. International Pig Topics, Mount Morris, v. 18, n. 7, p.11-13, 2003.

FLEMMING,J.S.; FREITAS,R.J.S. Avaliação do efeito de prebiótico (MOS), probióticos (Bacillus licheniformis e Bacillus subtillis) e promotor de 
crescimento na alimentação de frangos de corte. Arch Vet.Scie. Curitiba. V.10,n. 2, p.41-47. 2005.

GRIGOLETTI, C.; FRANCO, S. G.; FLEMMING. J. S.; BACILA, M. Saccharomyces cerevisae na alimentação de frangos de corte. Archives of Veterinary Science, Curitiba, v. 7, n. 2, p. 151-157, 2002.

GUO, Y; LIU. C. Impact of heat stress in broiler chicks and effect of supplemental yeast chromium. Biotecnology Science, London, n. 13, p. 2-4, 1997.

HALFHIDE, B. Role of probiotics in animal nutrition and their link to the demands of European consumers. In: ROLE OF THE EUROPEAN PROBIOTIC ASOCIATION. Proceedings... Needertlands, p. 3 - 4, 2003.

ITO, N. M. K.; MIAJI, C.I.; LIMA, A E.; OKABAHASHI, S. Saúde gastrointestinal, manejo e medidas para controlar as enfermidades gastrointestinais. In: PRODUÇÃO DE FRANGOS DE CORTE, 2004, Campinas. Anais... Campinas: FACTA. 2004. p 206-260.

LATRILLE, L. L. RIQUELM,C.G.; MATEROLA, H.B.; POLAMINOS S.M. Evaluation de dos tipos de leveduras como fuente proteica para raciones de pollos em crescimiento. Avance en producion Animal, Casila, v. 1, p. 45-51, 1996.

LINE, J. E. MIAJI,C.I.; LIMA, A E. Effect of yeast suplemental feed on Salmonella and Campylobacter populations in broiler. Poultry Science, Champaign, v.7, p.405-410, 1998.

MARTIN, S. C. Potential for manipulating the gastrointestinal microflora : A review of recent progress. In: BIOTECNOLOGY IN THE FEED INDUSTRY OF ANNUAL SYMPOSIUM, 10., 1994. Proceedings... London: Nottingham University Press, 1994, p. 155-166.

MAPA - Instrução Normativa no 65/2006 de 24/11/2006 publicada no em DOU 24.11.2006, em www.agricultura.gov.br acessos em 18.01.2009..

MILTEMBURG, G. Promotores e aditivos de crescimento em Avicultura. In: CONFERENCIA APINCO DE CIÊNCIA E TECNOLOGIA AVICOLAS, 2000, Campinas. Anais... Campinas: FACTA, 2000. p. 204-215.

NEWMAN, K. Mannanologosaccharides: Natural polynmers whith significant impact on the gastrointestinal microflora and the immune system. In: BIOTECNOLOGY IN THE FEED INDUSTRY ANNUAL SYMPOSIUM, 10., 1994. Proceedings... London: Nottingham University Press, 1994, p. 155166.

OKPOKWASILI, N. P. The effect of substitution of fish meal by brewers yeast in broiler starter rations in the tropics. Bulletin of Animal Health and
Production in Africa, Nairobi, v. 44, p. 71-72, 1996.

PELICIA, K. Use of probiotics and prebiotics to bacterial and yeast origin for free-range broiler chikens. British Journal of Poultry Science, London, v. 6, n. 3. 163-169. 2004.

ROSS BREEDERS. Producing quality meat. Newbridge, U.K. Ross Breeders Limited. 52 p. 1990.

REIG, A. L. C.; ANESTO, J. B. Prebióticos y probióticos una relación benefiosa. Revista Cubana de Alimentación y Nutrición, Havana, n. 16. p. 63-68 . 2002.

SAS Institute.SAS® (Statistical Analysesis System) User's Guide: Statistiis.Cary N.C. SAS Institute Inc. 1998.

SANTIN, E.; MAIORKA, A.; MACARI, M.. Performance and intestinal mucosa development of broiler chickens fed diets containing Saccharomyces cerevisae cell wall. Journal of Applied Poultry Research, Champaign, v. 10, p. 236-244, 2001.

SEVERO, M. P. F. Plano de controle de resíduos em produtos de origem animal no Brasil: Ministério da Agricultura e Abastecimento. In: CONFERENCIA APINCO DE CIÊNCIA E TECNOLOGIA AVICOLAS, 2000, Campinas. Anais... Campinas: FACTA, $2000 . \quad$ p. 242-251.

SILVA, E. N. Probióticos e Prebióticos na Alimentação de Aves. In: CONFERENCIA APINCO DE CIÊNCIA E TECNOLOGIA AVICOLAS, 2000, Campinas. Anais... Campinas: FACTA, 2000. p. 242-251.

SOERJADI, A S.; SNOYENBOS, G. H.; WEINACK, O. M. Intestinal colonization and competitive exclusion of Campylobacter and E.coli in young chickens. Avian Diseases, Ithaca, n. 25, v. 3, p. 1456-1462, 1992.

SPRING, P.; WEEK, C.; DAVESON, K. A; NEWMANN, K.E. The effect of diet mananoligosaccharides on cecal parameters and concentration of enteric bacteria in the cecal of Salmonella changed in broiler diets. Poultry Science, Champaign, v. 79, p. 205-211, 2000.

STAT 2.0. Sistema de Análise Estatística. Jaboticabal: UNESP. Polo Computacional do Departamento de Ciências Exatas, 1992

SUBRATA, S.; MANDAL, L.; BANEERJEE, G.C.; SARKAR, S. Effect of feeding yeast and antibiotics on the performance of broilers. Indian Journal Poultry Science, v.32, n. 2, p.126-131, 1997. 